\title{
Modeling and Simulation Vehicle Air Brake System
}

\author{
Li He, Xiaolong Wang, Yunqing Zhang, Jinglai Wu, Liping Chen \\ CAD Center, Huazhong University of Science and Technology, China \\ zhangyq@hust.edu.cn
}

\begin{abstract}
Air brake system has been widely used in heavy trucks and intercity buses for its great superiority over other brake system. The practical performance of air brake system may be greatly different from if we analyze it with static theory. Thus, it is necessary to build an integrate air brake system model to simulate the process of brake accurately. However, the dynamic mathematic model of air brake system is very complicate, which makes the model hard to be solved. In this paper, the components of air brake system are decomposed to several basic standard pneumatic components, and then build the system based on these basic standard pneumatic components. The standard pneumatic components which are built in the softwareMWorks based on Modelica language include cylinder, nozzle, air reservoir, volume, and air pipe. An air brake system which contains brake valve, relay valve, brake chambers and pipelines is made based on the standard pneumatic components. The simulation results show the dynamic characteristics of air brake system.
\end{abstract}

Keywords: air brake system; dynamic model; Modelica

\section{Introduction}

Brake system affects the safety of automotive directly. The theories of brake system have been well studied [1, 2, 3]. However, the theories of brake system are almost limited to analyze the system's static characteristics such as the distribution of brake force between the front and rear axle, brake efficiency and so on. There is little literature focus on the dynamic characteristics of brake system.
The vehicle brake system can be generally divided into hydraulic brake system and air brake system. In fact, most tractor-trailer vehicles with a gross vehicle weight rating (GVWR) over $19000 \mathrm{lb}$, most single trucks with a GVWR over $31000 \mathrm{lb}$, most transit and intercity buses, and about half of all school buses are equipped with air brake systems [4]. Generally, the air brake system will show longer delay time than the hydraulic brake system for the response of air pressure is relative slowly to hydraulic pressure. In fact, the delay time for the pressure response has enormous influence on the performance of the vehicle brake system. Also the quick pressure response is one of the most important indispensible working conditions for the anti-brake system (ABS) which has been widely used in automotives. Thus, to shorten the pressure response time is necessary. Roudlf [1] has given an empirical equation to calculate the delay time for the pressure response in air brake system, which correlated with the brake chamber volume and the length of pipelines. However, in practice we often need a more accurate model to research the delay time more exactly. So the model of air brake system which can accurately predict the pressure transmits from reservoir along the brake pipelines to the brake valve, relay valve and brake chamber should be build.

The mathematic model for dynamic responses of air brake system is very complicated since many differential equations need to be solved and many parameters may be correlated with each other, especially the parameters for the key components, such as brake valve, relay valve and pipelines. A non-linear model of the pneumatic subsystem of the air brake system which relates the pressure in the brake chamber to the brake valve plunger displacement and the supply pressure to the brake valve has been developed in $[5,6]$. The mathematic model is very compli- 
cated, which leads it hard to be solved. Wu [7] studied the robust of pneumatic brake system in commercial vehicle, where the dynamics model is built in software-AMESim. In this paper, we use the Modelica language $[8,9]$ to construct the mathematic model, and we do not need to focus on the solver, which simplifies the work largely.

In this study, the pneumatic brake system model are built and simulated based on the Modelica language. In section 2, the constitutions of air brake system are presented; the air brake system model is introduced in section 3 . The simulation results are shown in section 4 , and some conclusions are presented in the last section.

\section{Air brake system components}

An essential layout of the air brake system of a commercial vehicle is shown in Fig.1. The air brake system contains air compressor, storage reservoirs, brake valve, relay valve, brake chambers and some brake lines.

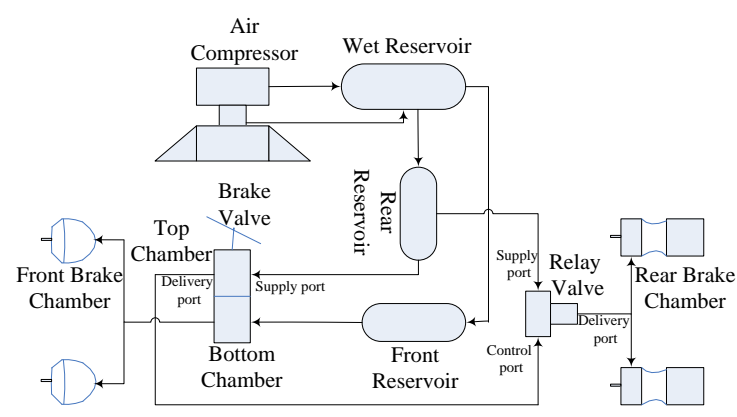

Figure. 1 Schematic representation of an air brake system

The driver applies the brake by pressing the brake pedal on the brake valve. This action makes the compressed air flow from the supply port of the brake valve to its delivery port. For the front circuit, the compressed air travels from the delivery port in bottom chamber of the brake valve through pipelines to the front brake chambers mounted on the front axles. For the rear circuit, the compressed air travels from the delivery port in top chamber of the brake valve through pipelines to the control port of relay valve, which opens the supply port of relay valve and makes the air flow to the rear brake chambers mounted on the front axles.

\subsection{Brake Valve}

The structure of brake valve is shown in Fig. 2.

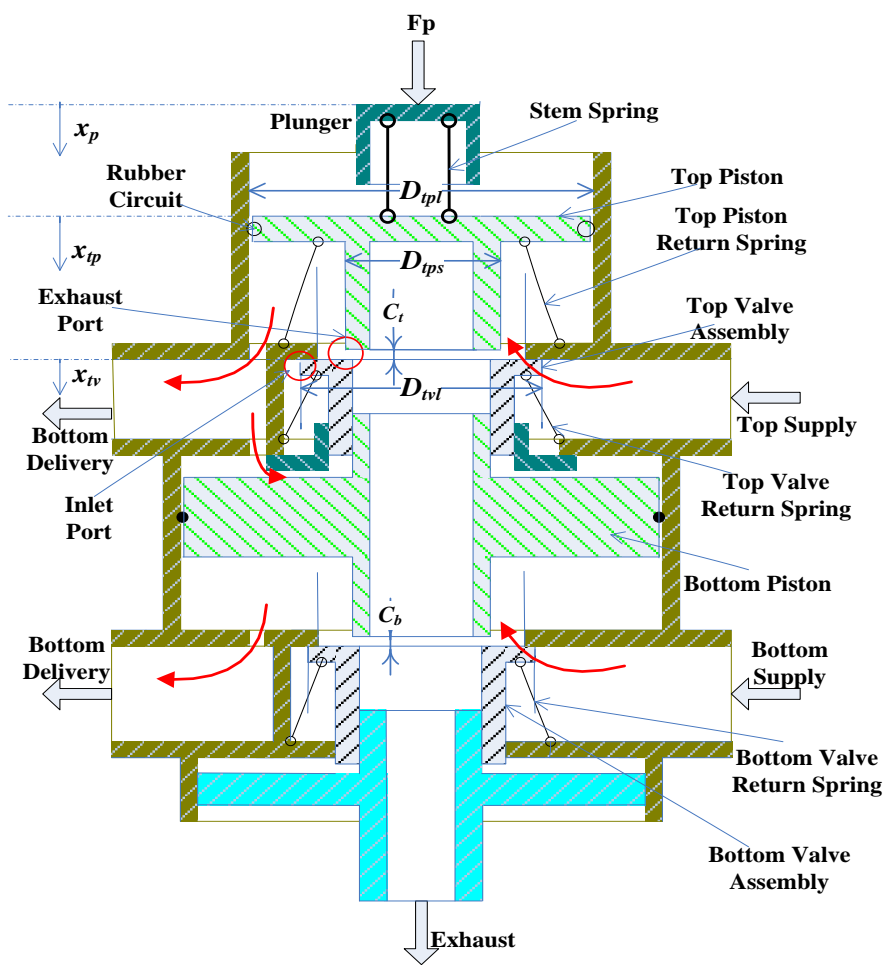

Figure. 2 Structure of brake valve

There are two supply ports, two delivery ports, and an exhaust port in the brake valve. The top supply port and bottom supply port are connected to rear reservoir and front reservoir respectively, while the top delivery port and bottom delivery port are connected to relay valve and front chambers respectively. For the top chamber, when the driver applies pedal force to the plunger, the force transmits to top piston compressing the rubber plunger spring. If the force acted on top piston is larger than the preload and friction, the top piston will move down. The exhaust port will be closed when the top piston touches the top valve, and the inlet port will open if the force transmitted to top valve can overcome the preload on top valve. Then the compressed air in rear reservoir can flows into top chamber, which makes the pressure in top chamber increasing. The compressed air in top chamber will produce a force that makes the top piston and top valve move up, and the inlet port will be closed gradually. The pressure keeps constant for both the inlet port and exhaust port are closed, thus the air pressure in top chamber 
keeps constant. If the driver reduces pedal force, the balance of top piston will be broken. The top piston moves up for the force made by compressed air larger than pedal force, which make the exhaust port opened. Thus, the compressed air flow to atmosphere and reduces the pressure. The apply process of bottom chamber is similar to the top chamber.

The flow areas of inlet port and exhaust port have important effect on the characteristics of brake valve. The positions of top piston and top valve determine the flow areas of inlet port and exhaust port, expressed by the following equations.

$$
\begin{aligned}
& A_{i n}= \begin{cases}0 & x_{t p} \leq C_{t} \\
\pi D_{t v l}\left(x_{t p}-C_{t}\right) & x_{t p}>C_{t}\end{cases} \\
& A_{e x}= \begin{cases}\pi D_{t p s}\left(C_{t}-x_{t p}\right) & x_{t p} \leq C_{t} \\
0 & x_{t p}>C_{t}\end{cases}
\end{aligned}
$$

Where $C_{t}$ denotes the exhaust clearance, $D_{t v l}$ and $D_{t p s}$ are the geometry dimensions shown in Fig. 2, $x_{t p}$ is the displacement of top piston.

\subsection{Relay Valve}

The structure of relay valve is similar to the brake valve, shown in Fig. 3.

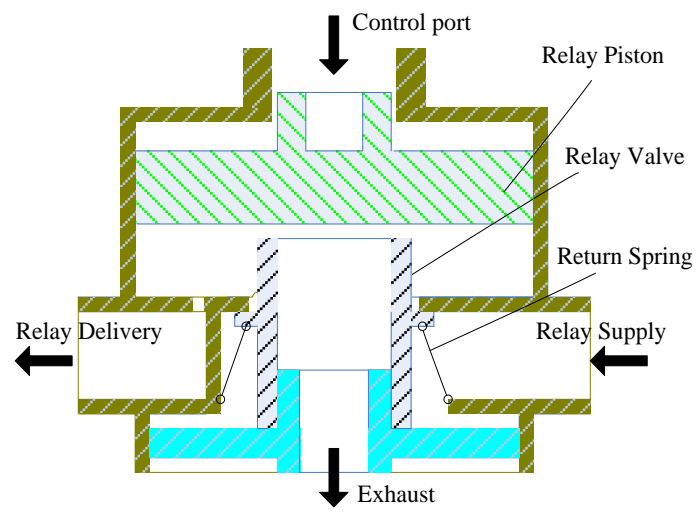

Figure. 3 Structure of relay valve

The difference between the brake valve and relay valve is that the control signal for brake valve is the force supplied by pedal while the control signal for relay valve is the compressed air from the brake valve. Relay valve can shorten the delay time for the rear brake chambers which are far from the brake valve.

\subsection{Brake Chamber}

Brake chamber is the component transiting air pressure to mechanical force. When the compressed air flows to the brake chamber, the air pressure pushes the push rod move, and then the mechanical force is transmitted to brake drum which makes the vehicle decelerated. In this paper, we simplify the rear service and spring brake chamber as the front service brake chamber (see Fig. 4).

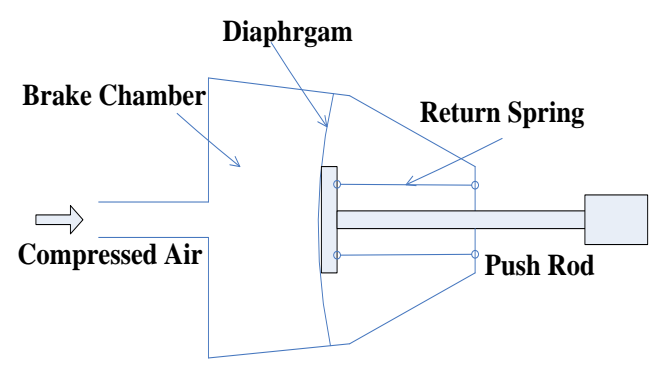

Figure. 4 Structure of brake chamber

\section{Modeling vehicle air brake system}

\subsection{Standard pneumatic components}

The standard pneumatic components include air volume, cylinder, nozzle, and pipe. We assume that the air temperature in volume is constant, and the thermal dynamic process is called isothermal. When the air flows to a constant volume, the pressure in the volume can be described by:

$$
P=m R T / V
$$

Where $P$ denotes the pressure, $m$ denotes the air mass in the volume, $R$ denotes the ideal gas constant, $T$ is the temperature, and $V$ is the volume.

The cylinder is still assumed as isothermal, but the volume is not constant. The volume can be expressed as

$$
V=V_{0}+A_{c} s_{p}
$$

Where $V_{0}$ denotes the initial volume of cylinder chamber, $A_{c}$ is the effective area of piston, and $s_{p}$ denotes the displacement of piston. 
The nozzles in pneumatic system can be modeled as restrictions. The air flows from highpressure chamber (upstream) to low-pressure chamber (downstream), the mass flow rate for the nozzle can be expressed by

$$
\dot{m}=A C_{q} C_{m} \frac{P_{u}}{\sqrt{T_{u}}}
$$

Here, $A$ is the flow area of nozzle, and $C_{q}$ is the flow coefficient which can be expressed as

$$
\begin{aligned}
C_{q}= & 0.8414-0.1002\left(\frac{p_{d}}{p_{u}}\right)+0.8415\left(\frac{p_{d}}{p_{u}}\right)^{2}-3.9\left(\frac{p_{d}}{p_{u}}\right)^{3} \\
& +4.6001\left(\frac{p_{d}}{p_{u}}\right)^{4}-1.6827\left(\frac{p_{d}}{p_{u}}\right)^{5}
\end{aligned}
$$

$C_{m}$ is the flow parameter can be expressed by [7, $8,10,11]$

$C_{m}= \begin{cases}\sqrt{\frac{2}{R} \cdot \frac{\gamma}{\gamma-1}} \cdot \sqrt{\left(\frac{P_{d}}{P_{u}}\right)^{2}-\left(\frac{P_{d}}{P_{u}}\right)^{\frac{\gamma+1}{\gamma}}}, & \text { if } \frac{P_{d}}{P_{u}}>P_{c r}=\left(\frac{2}{\gamma+1}\right)^{\frac{\gamma}{\gamma-1}} . \\ \sqrt{\frac{2}{R} \cdot \frac{\gamma}{\gamma-1}} \cdot\left(\frac{2}{\gamma+1}\right)^{\frac{1}{\gamma-1}}, & \text { if } \frac{P_{d}}{P_{u}} \leq P_{c r}=\left(\frac{2}{\gamma+1}\right)^{\frac{\gamma}{\gamma-1}}\end{cases}$

Where $\gamma$ denotes the specific heat ratio, $P_{c r}$ dentoes critical pressure ratio, $P$ and $T$ denote the pressure and temperature respectively, subscript $u$ and $d$ denote upstream and downstream respectively. The pipelines can also be modeled as restriction.

\subsection{Air brake components}

Build the air brake components models based on the standard pneumatic model in softwareMWorks. The top chamber of brake valve is shown in Fig. 5.

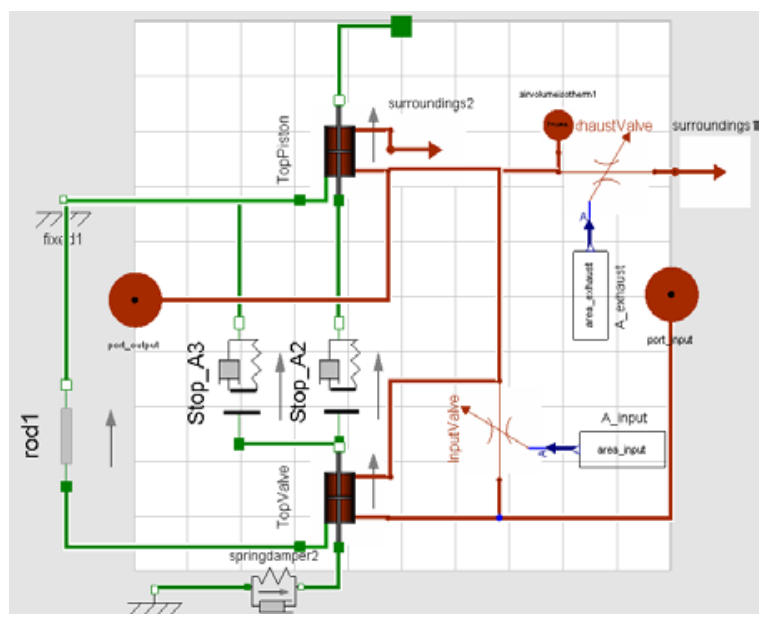

Figure. 5Structure of top chamber
The bottom chamber of brake valve is shown in Fig. 6.

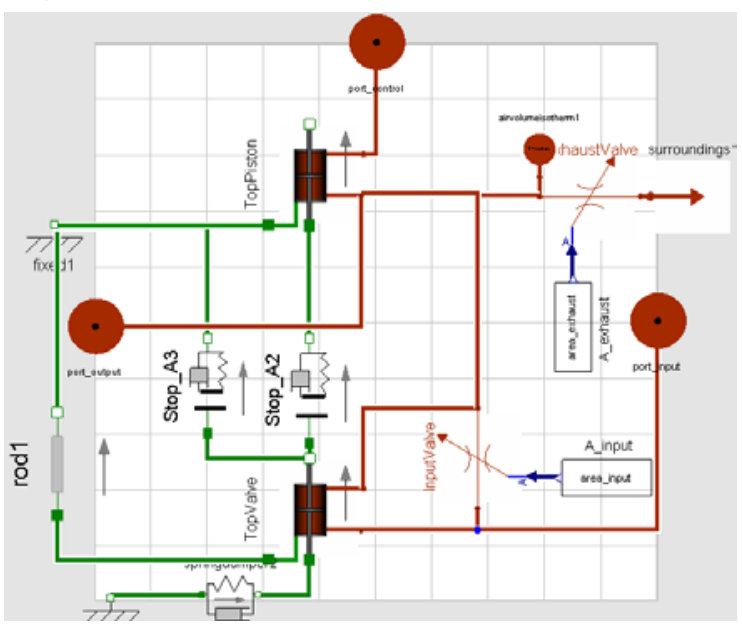

Figure. 6 Structure of bottom chamber

The structure of relay valve is the same as the bottom chamber of brake valve, so we would not repeat it. Build the brake chamber based on the standard pneumatic model, shown in Fig. 7.

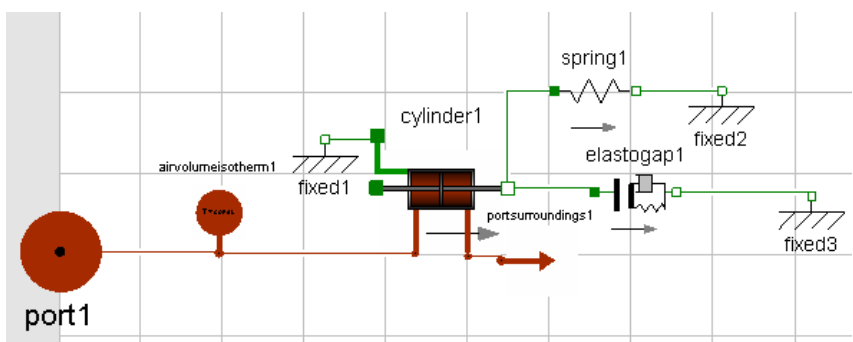

Figure. 7(a) Structure of brake chamber

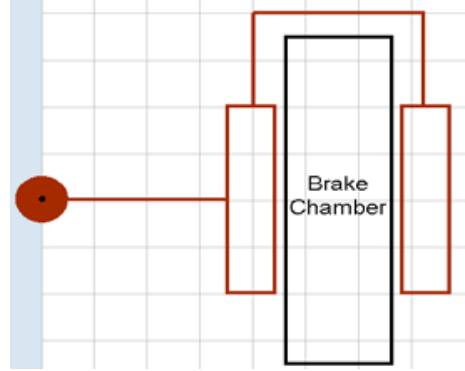

Figure. 7(b) Icon of brake chamber

\subsection{Air brake system}

Based on the components of air brake system, construct the air brake system shown in Fig. 8. 


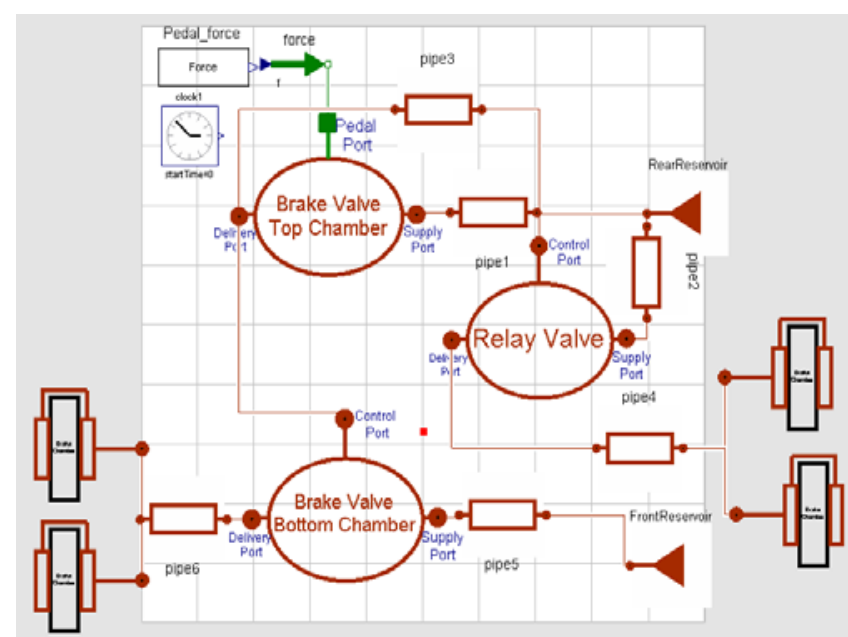

Figure. 8 Air brake system

\section{Simulation results}

Take the plunger force (enlarged pedal force) as input signal and the pressure of air in brake chamber as the output signal. Figure. 9 shows a specified plunger force variation curve. The plunger force increases to $1200 \mathrm{~N}$ from $0 \mathrm{~N}$ during the period between 0 second and 0.4 second (apply phase), keep the force unchanged until the time at 4 second (hold phase), and reduce the force to $0 \mathrm{~N}$ during the period between 4 second and 4.4 second (exhaust phase).

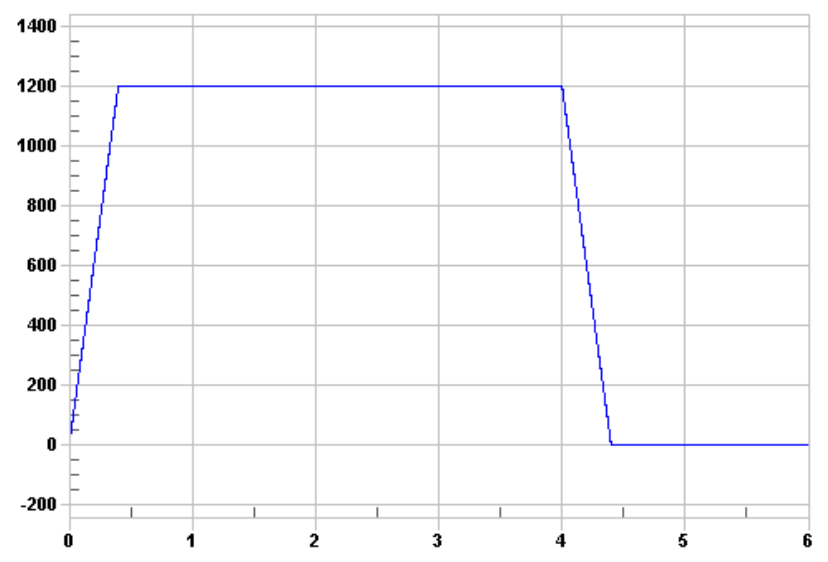

Figure. 9 Plunger force

The pressure in brake chambers are shown in Fig. 10. The blue line denotes the pressure in front brake chamber, and red line denotes the pressure in rear brake chamber.

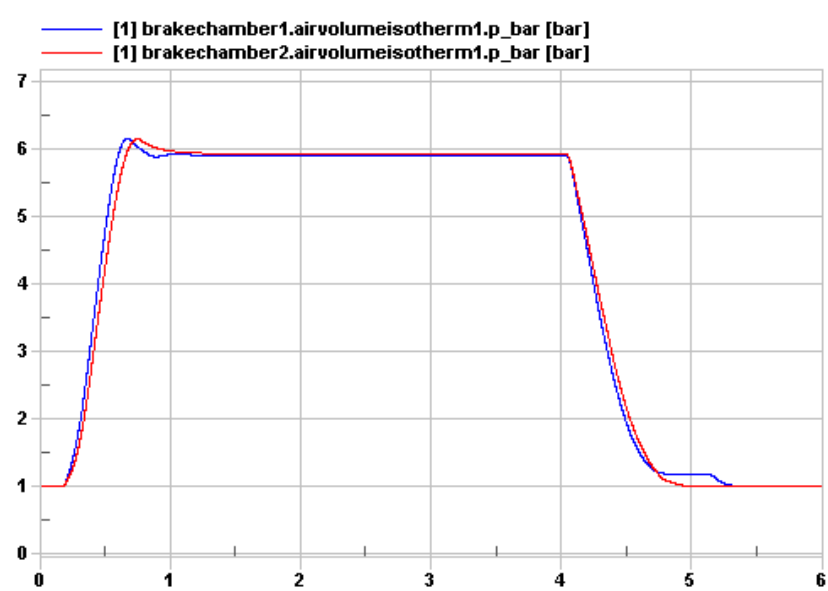

Figure. 10 Pressure in brake chamber

From the simulation results, we find that the pressure in brake chamber is consistent with the plunger force, but the pressure variation delays to the plunger force. Through the simulation, we can research the dynamic response of air brake system further.

\section{Conclusions}

The dynamic model of air brake system is presented in this paper. The mathematic models of some standard pneumatic components are introduced and built in software- MWorks. The key components of air brake system such as brake valve, relay valve, and brake chamber are constructed based on the standard pneumatic components. The integrate air brake system is also built using the key components, and the simulation results show dynamic characteristics of air brake system. Through the dynamic simulation, the delay time of brake system can be obtained more accurately, which has helpful to improve the performance of air brake system.

\section{Acknowledgement}

This work was supported by the National High-Tech R\&D Program, China (No. 2009AA044501).

\section{References}

[1] Limpert. R. Brake Design and Safety. SAE Order No. R-198, 1999. 
[2] Limpert. R. Engineer Design Handbook, Analysis and Design of Automotive Brake Systems. US Army Material Development and Readiness Command, DARCOM-P 706-358, 1976.

[3] Bert. B, Karlheinz. H. Brake Technology Handbook. SAE Order No.R-367, 2008.

[4] Williams. S. F, Knipling. R. R. Automatic Slack Adjusters for Heavy Vehicle Air Brake Systems. Nat. Highway Traffic Safety Administration, Washington, DC, Tech. Rep. DOT HS 807 724, Feb 1991.

[5] Subramanian. S. C, Darbha. S, and Rajagopal. K. R. A Diagnostic System for Air Brakes in Commercial Vehicles. IEEE Transactions on Intelligent Transportation Systems, Vol.7, No.3, September 2006, pp360-376.

[6] Subramanian. S. C, Darbha. S, and Rajagopal. K. R. Modeling the Pneumatic Subsystem of an S-cam Air Brake System. Trans. of the ASME, J. of Dynamic Systems, Measurement, and Control, Vol.126, 2004, pp3646.

[7] Wu. J, Zhang. H, Zhang. Y, Chen. L. Robust design of pneumatic brake system in commercial vehicles. SAE, 2009-01-0408.

[8] Fritzson P., Vadim V. Modelica -- A Unified Object-Oriented Language for System Modeling and Simulation. Proceedings of the 12th European Conference on ObjectOriented Programming, 1998, pp.67 - 90.

[9] Zhou F, Chen L. and Wu Yi., etc. MWorks: a Modern IDE for Modeling and Simulation of Multidomain Physical Systems Based on Modelica. Modelica 2006, September 4th $5^{\text {th }}$, pp. 725-732.

[10] Bowlin. C. L, Subramanian. S. C, Darbha. S, and Rajagopal. K. R. Pressure Control Scheme for Air Brakes in Commercial Vehicles. IEE Proc. Intelligent Transportation Systems, Vol. 153, No.1, March 2006, pp2132.

[11] Peter. B. Pneumatic Drives. Springer-Verlag Berlin Heidelberg, 2007.

[12] Burrows C R, Peckham R G (1977) Dynamic characteristics of a pneumatic flapper valve. Journal Mechanical Engineering Science. 19(3):113-121. 